\title{
Molecular epidemiology of drug resistance markers of Plasmodium falciparum in Yunnan Province, China
}

\author{
Fang Huang ${ }^{1}$, Linhua Tang ${ }^{1 *}$, Henglin Yang ${ }^{2}$, Shuisen Zhou' ${ }^{1}$ Hui Liư ${ }^{2}$ Junwei Li ${ }^{1}$ and Shaohua Guo ${ }^{1}$
}

\begin{abstract}
Background: The mutations in Plasmodium falciparum chloroquine resistance transporter (pfcrt), multidrug resistance 1 (pfmdr1), dihydrofolate reductase (pfdhfr), dihydropteroate synthase (pfdhps) and ATPase (pfatp6) genes were associated with anti-malaria drug resistance. The aim of this study was to investigate the prevalence of polymorphisms in pfcrt, pfmdr1, pfdhfr, pfdhps and pfatp6 in Yunnan Province. Finger-prick blood samples were collected from malaria-positive patients from Yunnan Province in 2009-2010. Single-nucleotide polymorphisms (SNPs) in the resistance-related genes were analysed by various PCR-based methods.

Results: A total of 108 blood samples were collected. Although chloroquine has not been used to treat falciparum malaria for nearly 30 years, $95.3 \%$ of the parasites still carried the pfcrt K76T mutation, whereas the majority of isolates displayed the wild-type pfmdr1 N86 and D1246 sequences. The molecular level of sulphadoxine-pyrimethamine resistance in P. falciparum was high. The most prevalent mutation was pfdhfr C59R (95.9\%), whereas the frequencies of the quadruple, triple and double mutants were 22.7\% (N51I/C59R/S108N/164L), 51.5\% (N511/C59R/S108N, N511/C59R/1164L and C59R/S108N/ 1164L) and 21.6\% (N51I/ C59R, C59R/S108N and C59R/1164L), respectively. A437G $(n=77)$ and K540E $(n=71)$ were the most prevalent mutations in pfdhps, and $52.7 \%$ of the samples were double mutants, among which A437G/K540E was the most common double mutation (37/49). Quadruple mutants were found in 28.0\% (26/93) of samples. A total of $8.6 \%$ of isolates (8/93) carried the S436A/A437G/A581G triple mutation. No mutations were found in pfatp6 codons 623 or 769 , but another two mutations (N683K and R756K) were found in 4.6\% (3/97) and 9.2\% (6/97) of parasite isolates, respectively.

Conclusions: This study identified a high frequency of mutations in pfcrt, pfdhfr and pfdhps associated with CQ and $\mathrm{SP}$ resistance in $P$. falciparum and no mutations linked to artemisinin resistance (pfatp6). Molecular epidemiology should be included in routine surveillance protocols and used to provide complementary information to assess the appropriateness of the current national anti-malarial drug policy.
\end{abstract}

\section{Background}

Malaria is a major health problem in Southeast Asia, where 1.3 billion people are at risk, and it causes approximately 120,000 deaths each year [1]. Despite significant reductions in the overall malaria burden in the 20th century, the disease still represents a significant public health problem in China, especially in Yunnan Province [2]. In 2010, the Ministry of Health in China launched

\footnotetext{
* Correspondence: ipdtlh@sh163.net

${ }^{1}$ National Institute of Parasitic Diseases, Chinese Center for Disease Control and Prevention, WHO Collaborating Centre for Malaria, Schistosomiasis and Filariasis, Key Laboratory of Parasite and Vector Biology, Ministry of Health, Shanghai 200025, PR China

Full list of author information is available at the end of the article
}

an "action plan for malaria elimination", with the goals of eradicating local malaria cases in regions outside of the Yunnan border area by the end of 2015 and eliminating malaria in the entire country by the end of 2020 [3].

Falciparum malaria is now found in only two provinces in China, the Yunnan and Hainan Provinces [4]. Malaria control measures have been actively implemented for more than 30 years, and considerable success has been achieved; there have been no local cases of falciparum malaria in Hainan in the past two years [5]. However, the malaria situation in Yunnan Province near the Myanmar border remains serious. Yunnan Province is located in southern China; it includes 131 counties and borders 
Myanmar, Lao People's Democratic Republic and Vietnam. The majority of malaria cases are concentrated in several counties bordering Myanmar. The border with Myanmar is $1,997 \mathrm{~km}$ long and approximately 98 million individuals cross the border each year. Yunnan Province has an estimated population of 42.36 million, with about 35.52 million people residing in malaria-endemic areas. From 2005 to 2011, malaria incidence decreased across the province and the reported cases and deaths in the province population have declined from 13,239 cases and 37 deaths in 2005 to 1,216 cases and zero deaths in 2011 . Of 2,643 reported cases, $28 \%$ were caused by Plasmodium falciparum [6].

The first case of chloroquine (CQ) resistance in P. falciparum was found in Yunnan Province in 1973, and by the end of the 1970s, CQ resistance had spread widely [7-9]. Subsequently, sulphadoxine-pyrimethamine (SP) was introduced as the first-line drug for falciparum malaria treatment. This antifolate combination seemed to be an effective and reasonable alternative, but resistance to SP also developed soon after its introduction in China. Since 2001, the WHO has recommended the use of artemisinin-based combination therapy in all areas where $P$. falciparum is resistant to other anti-malarial medicines to optimize therapeutic effectiveness and delay the emergence of resistance. The WHO advocated a complete ban on artemisinin monotherapy for uncomplicated malaria in 2006 [10]. The national drug policy of China was updated in 2009, and the first-line drugs currently used to treat falciparum malaria is artemisininbased combination therapy (ACT), which includes dihydroartemisinin-piperaquine (DHA-PIP), artesunate + amodiaquine, artemisinin-naphthoquine phosphate and artemisinin-piperaquine [11].

Many factors have contributed to the development and spread of drug resistance, including gene mutations and drug pressure [12]. Molecular surveillance is a new technique that has been implemented over the past decades to provide complementary information to assess the appropriateness of current policies based on anti-malarial drugs [13]. Several molecular markers of $P$. falciparum resistance have been identified. The K76T allele in the CQ resistance transporter gene ( $p f c r t)$ is associated with CQ and amodiaquine treatment failure and could be used for the surveillance of clinical CQ resistance [14-16]. The Y86 allele of multidrug resistance gene 1 (pfmdr1) has been linked with CQ and amodiaquine resistance [17]. The role of dihydrofolate reductase (dhfr) and dihydropteroate synthase (dhps) mutations in the mechanism of resistance to SP drugs has been well described. Mutations associated with antifolate resistance have been identified in codons 436, 437, 540, 581 and 613 in the pfdhps gene and codons 108, 51, 59, 140, 16 and 164 in the pfdhfr gene. The quintuple mutant of pfdhfr (S108N, N51I and C59R) and pfdhps (A437G and $\mathrm{K} 540 \mathrm{E}$ ) were associated with a high relative risk of treatment failure, and this haplotype was suggested as a relevant molecular marker for failure of SP treatment in uncomplicated $P$. falciparum cases [18-21]. The sarco/endoplasmic reticulum $\mathrm{Ca}^{2+}$-ATPase ortholog of P. falciparum (pfatp6) was suggested to be involved in the mechanism of parasite resistance to artemisinin $[22,23]$. Specific point mutations in codons 769,623 and 431 were associated with artemisinin resistance [24].

In recent decades, malaria drug resistance surveillance in Yunnan Province has relied on in vitro and in vivo tests, whereas molecular epidemiological studies of drug resistance have only been conducted as limited studies [25,26] and have not been used as a routine surveillance tool in the national malaria programme. In this study, the prevalence of polymorphisms in pfcrt, pfindr1, pfdhfr, pfdhps and pfatp6 genes in blood samples obtained from P. falciparuminfected patients in Yunnan Province were determined.

\section{Methods}

\section{Sample collection and DNA extraction}

The study was reviewed and approved by the ethics committee of the Chinese Centre for Disease Control and Prevention (China CDC). Blood samples were collected from patients with uncomplicated $P$. falciparum infection prior to drug treatment. All of the patients came from township hospitals in Tengchong and Yingjiang Counties in year 2009-2010. The initial diagnosis was made by microscopic examination of Giemsa-stained thick blood films or a rapid diagnostic test. For each sample, approximately $200 \mu \mathrm{l}$ of finger-prick blood was spotted on a piece of Whatman 3M 903 filter paper and air dried. After the patients were confirmed as malaria, they would get DHA-PIP. The dried filters were stored in individual plastic bags at $-20^{\circ} \mathrm{C}$ until DNA extraction. Parasite DNA was extracted from the blood filters using a QIAamp DNA mini kit (Qiagen, Valencia, CA, USA).

\section{Genetic characterization of parasites}

Nested PCR [14,20,27] was used to amplify fragments of pfcrt, pfindr1, pfdhfr, pfdhps and pfatp6. The amplified products were purified from an agarose gel and sequenced with an automated DNA sequencer (ABI systems, PerkinElmer, France). Sequence alignments and analysis were carried out using Mega and BioEdit software. Amino acid sequences were compared with wild-type sequences. The sequences of the amplicons were aligned with 3D7 strain published data from the NCBI database by BLAST analysis.

\section{Results}

\section{Study sites}

Yingjiang and Tengchong Counties, which have the highest falciparum malaria incidence rates in China, are 
located in the Dehong and Baoshan Prefectures, respectively, in southwest Yunnan Province (Figure 1). In this study, four township hospitals bordering with Myanmar were selected to collect malaria samples. Of all of samples, 56 patients was local malaria cases and 52 patients were contracted from Kachin State of Myanmar.

\section{Prevalence of single-nucleotide polymorphisms in pfcrt}

Codons 71, 72 and 76 were successfully amplified in 106 of the 108 samples analysed. The mutation in pfcrt codon 76 was found in $95.3 \%(101 / 106)$ of parasite isolates, and mutations in codons 71 and 72 were found in $3.0 \%(3 / 101)$ of parasite isolates. The mutant haplotype CVIET in codons $72-76$ was identified in $3 \%$ (3/101) of samples and 5.0\% (5/101) contained the wild-type haplotype CVMNK.

Prevalence of single-nucleotide polymorphisms in pfmdr1 All of the samples were genotyped for $p f m d r 1$ at codons 86 and 1246. The majority of isolates displayed the wildtype pfmdr1 N86 and D1246 alleles. A total of 5.6\% (6/ 108) of isolates carried the mutant allele Y86, and $94.4 \%$ had the wild-type allele. No mutation in Y1246 was found.

\section{Prevalence in single-nucleotide polymorphisms} in pfdhfr and pfdhps

The single-nucleotide polymorphism (SNP) haplotype of the pfdhfr gene at codons $16,51,59,108,140$ and 164 is linked with $P$. falciparum pyrimethamine resistance. The pfdhfr gene was successfully amplified in 97 samples, four of which contained amino acid substitutions compared with the wild-type sequence. The most prevalent mutation was C59R (95.9\%). There were no mutations in codons 16 or 140 . A total of 38 of 97 isolates carried the wild-type N51 allele, while 55 carried the mutant I51 allele, and four had mixed alleles; 93 and 58 of 97 isolates had mutant R59 and N108, respectively. A total of $18.6 \%(18 / 97)$ of isolates carried the wild-type I164, while $75.3 \%(73 / 97)$ carried mutant L164, and 6 had mixed alleles (Table 1).

More than half $(51.5 \%)$ of the isolates had triple mutations, including N51I/C59R/S108N ( $\mathrm{n}=35)$, N51I/C59R/ I164L $(\mathrm{n}=20)$ and C59R/S108N/ I164L $(\mathrm{n}=21)$. The double mutants included N51I/ C59R $(n=5)$, C59R/ S108N $(n=6)$ and C59R/I164L $(n=10)$. A total of $22.7 \%$ (22/97) carried quadruple mutations at codons N51I/ C59R/S108N/I164L, and only one isolate had a single mutation at codon R59 (Figure 2).

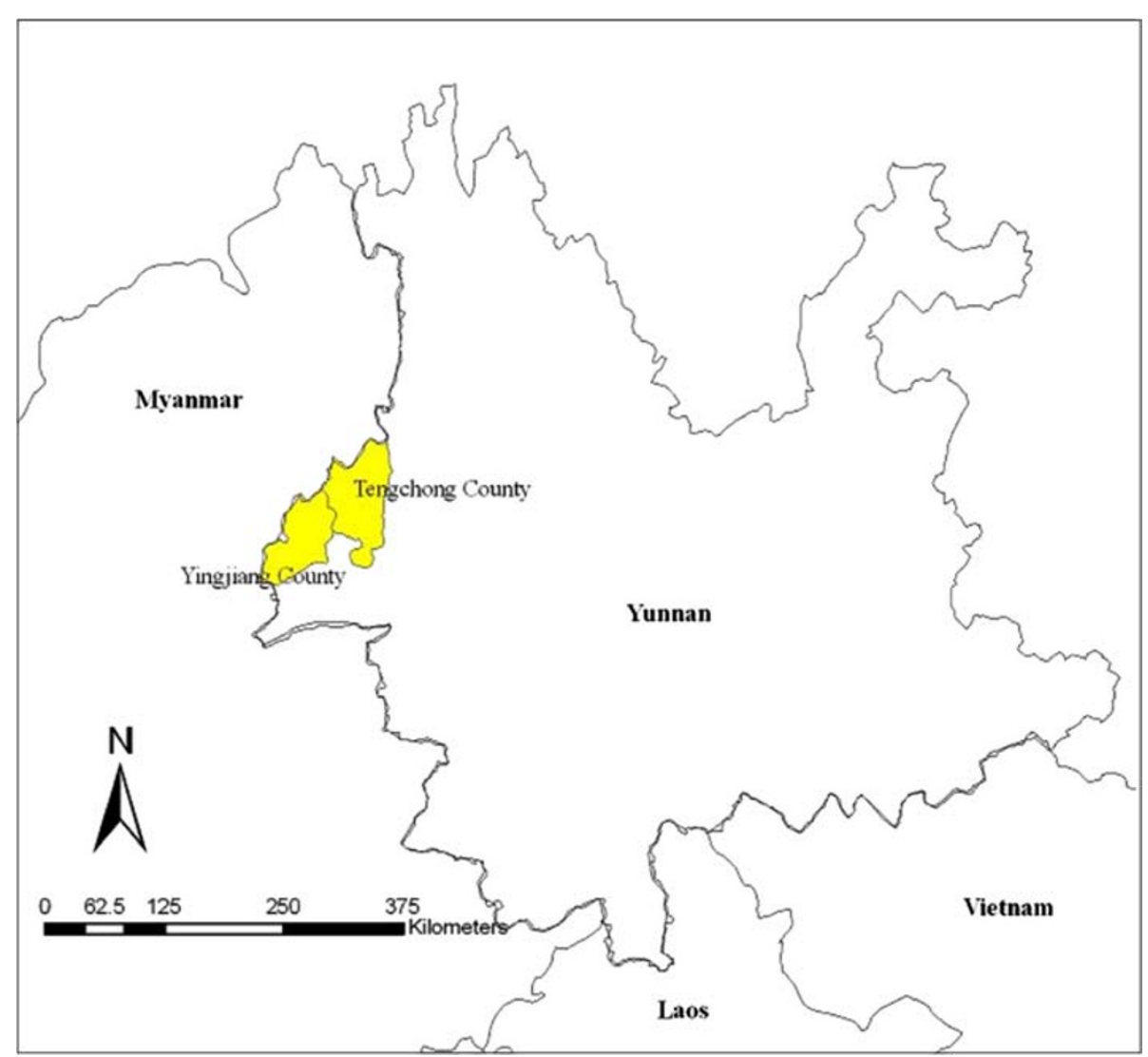

Figure 1 The location of Yingjiang and Tengchong Counties relative to neighbouring countries. 
Table 1 Prevalence of haplotypes of SNPs in pfdhfr and pfdhps in $P$. falciparum isolates from Yunnan Province

\begin{tabular}{|c|c|c|c|}
\hline Gene & Haplotypes & $\mathbf{N}$ & $\%$ \\
\hline \multirow[t]{4}{*}{ pfdhfr } & 151 & 59 & 72.3 \\
\hline & R59 & 93 & 95.1 \\
\hline & N108 & 96 & 94.1 \\
\hline & L164 & 79 & 85.3 \\
\hline \multirow[t]{6}{*}{ pfdhps } & I51/R59/N108 & 35 & 34.7 \\
\hline & A436 & 41 & 59.7 \\
\hline & G437 & 77 & 94.0 \\
\hline & E540 & 71 & 69.0 \\
\hline & G581 & 50 & 69.5 \\
\hline & G437/ E540 & 37 & 38.1 \\
\hline pfdhfr/pfdhps & I51/R59/N108+ G437/ E540 & 19 & 19.8 \\
\hline
\end{tabular}

A total of 93 parasite samples were genotyped for pfdhps polymorphisms at codons 436, 437, 540, 581 and 613, which are associated with $P$. falciparum sulphadoxine resistance. The A437G $(\mathrm{n}=77)$ and $\operatorname{K540E}(\mathrm{n}=71)$ mutants were most prevalent in pfdhps. A total of 52 isolates carried the wild-type S436 allele, and 41 had the mutant A436 allele. A total of $53.8 \%$ of samples carried the wild-type A581 allele, while $44.1 \%$ (50/93) had the G581 allele, and 2 isolates had mixed alleles (Table 1).

Double pfdhps mutants were found in $52.7 \%$ of isolates (49/93). The most prevalent double mutant was A437G/ K540E $(\mathrm{N}=37)$, followed by S436A/A437G $(\mathrm{n}=4), \mathrm{S} 436 \mathrm{~A} / /$ K540E $(\mathrm{n}=1), \mathrm{A} 437 \mathrm{G} / \mathrm{A} 581 \mathrm{G}(\mathrm{n}=3)$ and K540E/A581G $(\mathrm{n}=4)$. Quadruple mutants were found in $28.0 \%(26 / 93)$ of samples. A total of $8.6 \%(8 / 93)$ of samples were S436A/A437G/A581G triple mutants, and 10 isolates had a single mutation at A436 $(\mathrm{n}=4)$, E540 $(\mathrm{n}=5)$ or G581 ( $\mathrm{n}=1)$ (Figure 3).

Besides, the quintuple mutant of pfdhfr $(\mathrm{S} 108 \mathrm{~N}$, N51I and C59R) and pfdhps (A437G and K540E) were shown in Table 1, which werewere associated with a high relative risk of treatment failure, and this haplotype was suggested as a relevant molecular marker for SP resistance.

\section{Prevalence of single-nucleotide polymorphisms in pfatp6} No mutations in pfatp6 codons 623 or 769 were found, but another two mutations (N683K and R756K) were found in 4.6\% (3/97) and 9.2\% (6/97) of parasite isolates, respectively.

\section{Discussion}

Yunnan Province has experienced considerable economic development in the last 10 years; based on the appearance of villages at present compared with 19992000, the standard of living, even in rural areas, has improved considerably. During this time, there has also been a significant decline in the number of malaria cases reported. However, suspected artemisinin resistance occurring in Mekong areas and difficulties for mobile population management in bordering areas will presents a challenge for eliminating malaria in the entire country by the end of 2020 .

Pfcrt has been demonstrated to be a major determinant of CQ resistance in P. falciparum, and the K76T mutation has been widely used as a reliable marker for CQ resistance in epidemiological studies [28-30]. Since CQ resistance was first found in China, it has spread widely, prompting the use of ACT to treat falciparum malaria. According to a longitudinal survey conducted

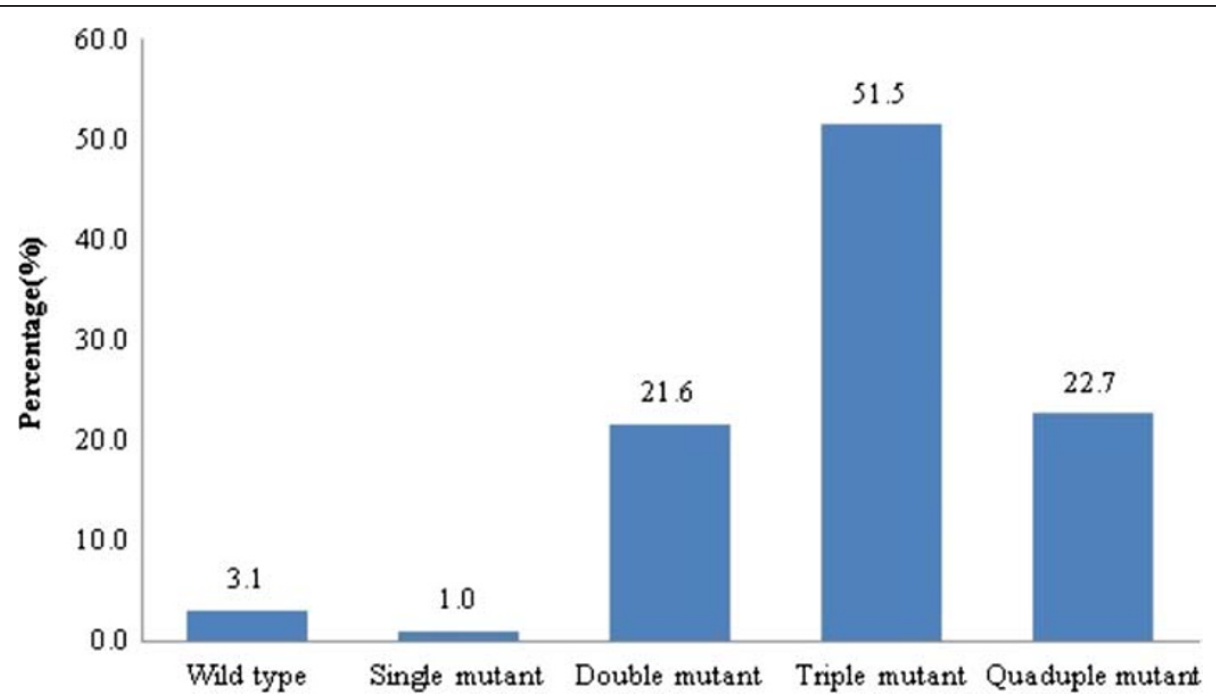

Figure 2 Frequency of pfdhfr haplotypes in samples from Yingjiang County. The frequency of the constructed haplotypes of SNPs in N511, C59R, S108N and 1164L of the pfdhfr gene is linked with Plasmodium falciparum pyrimethamine resistance $(n=97)$. 


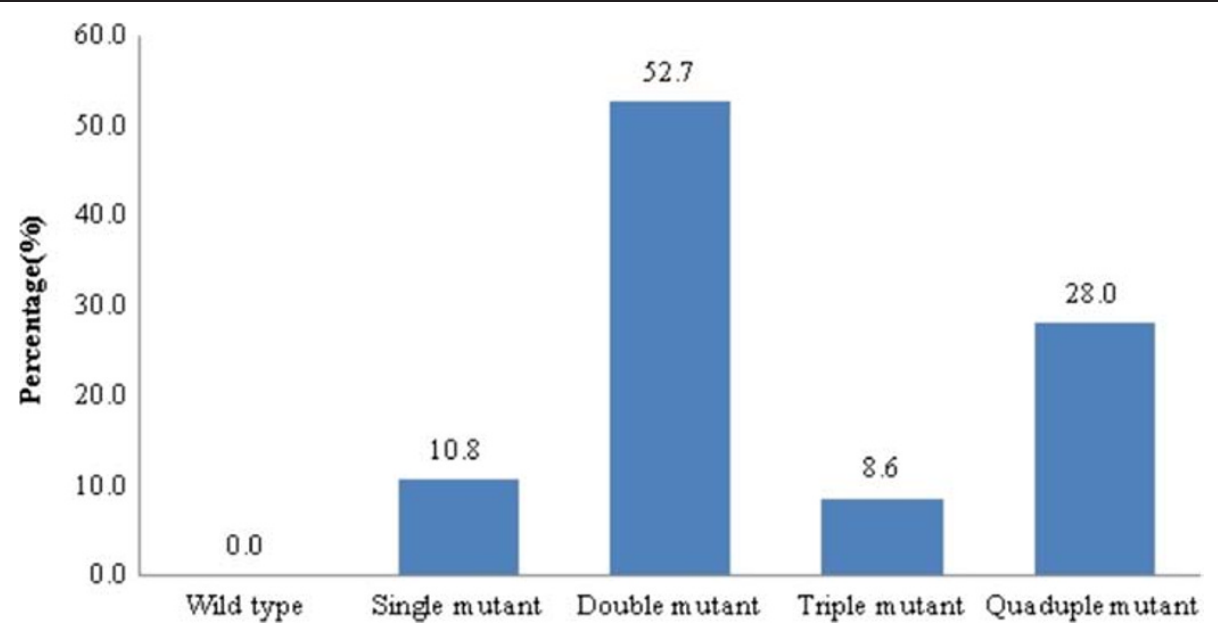

Figure 3 Frequency of pfdhps haplotypes in samples from Yingjiang County. The frequency of the constructed SNP haplotypes in the pfdhps gene at S436A, A437G, K540E and A581G is linked with Plasmodium falciparum sulphadoxine resistance $(n=93)$.

in the Yunnan and Hainan Provinces, which are endemic for falciparum malaria, the resistance of $P$. falciparum to CQ declined progressively after CQ use was stopped or reduced, as determined by in vitro tests [9,31]. However, the result of this study showed a high frequency of the K76T mutation of $p f c r t$, which is consistent with other studies conducted in China $[25,26]$. Several theories have been proposed for the persistence of the K76T mutation. The most important proposed reason was the wide use of CQ to treat Plasmodium vivax. Although CQ has not been used to treat $P$. falciparum in China for more than 30 years, the stable and high prevalence of $C Q$ resistance may be caused by the continued use of CQ as a first-line drug for the treatment of $P$. vivax. This factor may be responsible for the slow decline of $P$. falciparum CQ resistance in Southeast Asia, especially in the Mekong sub-region [32,33].

Compared with the high prevalence of the pfcrt mutation, few samples had mutations in codon 86 and no mutations were found in codon 1246 of $p f m d r 1$. This result was consistent with the findings of other researchers $[25,26,34,35]$. The Y1246 allele of $p f m d r 1$ was not related with CQ resistance, which was not consistent with the results in Africa [36]. However, the prevalence of the mutation at Y86 was still high in parasite isolates from some countries in Southeast Asia. Pfmdr1 mutations differentially affected the $C Q$ responses in $C Q$ resistance parasites and their activities depending on the pfcrt haplotype to which they were associated $[37,38]$, and pfmdr1 gene copy number amplifications and most of the $p f m d r 1$ gene amplifications in field samples harbors an asparagine at 86 amino acid position of $p f m d r 1$ gene $[39,40]$. Mefloquine has never been used in Yunnan Province, which would also be related to the low prevalence of mutation of the $p f m d r 1$ gene.
The role of pfdhfr and pfdhps mutations in the mechanism of resistance to SP drugs has been well described. Pyrimethamine was used for the radical treatment of P. vivax in combination with primaquine 40 years ago. Additionally, pyrimethamine added to salt was used for prophylaxis in the 1980s [30]. Pyrimethamine plus primaquine has always been recommended as prophylactic medicine for specific populations in China [6]. This study found that the prevalence of quadruple, triple and double mutant $P$. falciparum at the China-Myanmar border was still high. The finding of this study was similar to that in northeast Myanmar, Thailand and Cambodia, where highly mutated $p f d h f r$ and $p f d h p s$ genotypes were also common [41,42]. SP monotherapy was used for a short time after CQ resistance had spread widely, and artemisinin drugs were subsequently introduced and gradually became the standard of malaria therapy. However, it is unclear how to explain the discrepancy between the absence of SP pressure and the high prevalence of the pfdhfr triple mutants and pfdhps double mutants. it could be speculated that SP drugs were frequently used in bordering countries of the Mekong sub-region for long periods, and the frequent population migration across borders ensured high regional gene flow, including these drug resistance genes.

The mechanism of action of artemisinin remains controversial.In vivo artemisinin resistance has been proposed [43] and identified by the presence of significantly decreased parasite reduction rates, manifested clinically by markedly longer parasite clearance times from the body [44-47]. The molecular basis for this phenomenon is uncertain. One of the proposed mechanisms is the interaction with the sarcoplasmic reticulum $\mathrm{Ca}^{2+}$ ATPase6. The analysis of naturally occurring polymorphisms in pfatp6 in field isolates suggested that a polymorphism at 
codon 769 may be associated with the reduced susceptibility of these isolates to artemether in vitro [23]. Like other investigators, there were no polymorphisms in codons 263 and 769, described as the key amino acids for the interaction between pfatp6 and artemisinin [24]. However, two mutations (N683K and R756K) were identified in parasite isolates in this study, which has been found in Zanzibar and Tanzania [48], and no mutation in position 683 has been published previously [49]. Mutations observed in this study and previous studies $[50,51]$ could be indirectly implicated in artemisinin susceptibility. Although artemisinin resistance in western Cambodia seems to be a heritable genetic trait, none of the candidate genes suggested by earlier studies confer artemisinin resistance. A genome-wide approach using whole genome sequencing and transcriptome studies to identify the molecular basis of artemisinin resistance has been suggested [52].

\section{Conclusion}

This study reports the high frequency of mutations in pfcrt, pfdhfr and pfdhps, which are associated with CQ and SP resistance in P. falciparum, but no mutation linked with artemisinin resistance in pfatp6. Although, molecular marker of artemisinin resistance has not been identified yet, this result of other in vivo tests in Yunnan Province (unpublished data) indicates that current ACT drugs for $P$. falciparum treatment are still effective. In addition, molecular epidemiology should be part of routine surveillance to produce complementary information to assess the appropriateness of the current national anti-malarial drug policy.

\section{Competing interests}

The authors hereby certify that no conflict of interest of any kind occurred in the framework of this study.

\section{Authors' contributions}

FH was responsible for the molecular genetic analysis and data interpretation and drafted the manuscript. LT was responsible for the overall study and was involved in all stages of this study, including its design. HY was involved in the study design and coordination. SZ performed several of the molecular genetic studies and data analysis. HL participated in sample collection. JL and SG carried out the molecular analysis and sequence alignments. All the authors read and approved the final manuscript.

\section{Acknowledgements}

We thank two anonymous reviewers for valuable comments and suggestions. This work was supported by the WHO Mekong Malaria Programme (WP/10/MVP/005837) and a project supported by the Chinese Centre for Disease Control and Prevention for Young Scientists (grant no. 2011A105).

\footnotetext{
Author details

${ }^{1}$ National Institute of Parasitic Diseases, Chinese Center for Disease Control and Prevention, WHO Collaborating Centre for Malaria, Schistosomiasis and Filariasis, Key Laboratory of Parasite and Vector Biology, Ministry of Health, Shanghai 200025, PR China. ${ }^{2}$ Yunnan Institute of Parasitic Diseases, Puer 665000, PR China.
}

Received: 14 May 2012 Accepted: 22 July 2012

Published: 28 July 2012

\section{References}

1. Malaria Disease Burden in SEA Region: [http://www.searo.who.int/EN/ Section10/Section21/Section340_4018.htm].

2. Tang LH: Progress in malaria control in China. Chin Med J 2000, 115:69-92.

3. China action plan for malaria elimination. http://www.moh.gov.cn/ publicfiles/business/htmlfiles/mohjbyfkzj/s3593/201005/47529.htm

4. Zhou SS, Wang Y, Fang W, Tang LH: Malaria situation in the People's Republic of China in 2008. Chin J Parasitol Parasit Dis 2009, 27:455-457.

5. Zhou SS, Wang Y, Li Y: Malaria situation in the People's Republic of China in 2010. Chin J Parasitol Parasit Dis 2011, 29:401-403.

6. Malaria Surveillance Project in China. Beijing: Ministry of Health; 2005.

7. Liu DQ, Liu RJ, Ren DX, Gao DQ, Zhang CY, Qiu CP, Cai XZ, Ling CF, Liang $\mathrm{AH}$, Tang $\mathrm{Y}$ : Alteration in resistance of Plasmodium falciparum to chloroquine after cessation of chloroquine medication for twelve years. Zhongguo Ji Sheng Chong Xue Yu Ji Sheng Chong Bing Za Zhi 1992, 10:241-244

8. Liu DQ, Liu RJ, Ren DX, Gao DQ, Zhang CY, Qiu CP, Cai XZ, Ling CF, Liang AH, Tang Y: Changes in the resistance of Plasmodium falciparum to chloroquine in Hainan, China. Bull World Health Organ 1995, 73:483-486.

9. Liu DQ, Feng XP, Yangh HL, Lin SG, Chen WJ, Yang PF: Fluctuation in the Resistance of Plasmodium falciparum to chloroquine in China. Chin J Parasitol Parasit Dis 2005, 23:27-31.

10. WHO: Guidelines for the treatment of malaria. Geneva: World Health Organization; 2010

11. Antimalarial drug policy in China. http://www.moh.gov.cn/publicfiles/ business/htmlfiles/mohjbyfkzj/s3594/200907/41610.htm.

12. Talisuna AO, Bloland P, D'Alessandro U: History, dynamics, and public health importance of malaria parasite resistance. Clin Microbiol Rev 2004, 17:235-254.

13. WHO: Methods for surveillance of antimalarial drug efficacy. Geneva: World Health Organization; 2009.

14. Djimde A, Doumbo OK, Cortese JF, Kayentao K, Doumbo S, Diourte Y, Dicko A, Su XZ, Nomura T, Fidock DA, Wellems TE, Plowe CV, Coulibaly D: A molecular marker for chloroquine-resistant falciparum malaria. N Engl J Med 2001, 344:257-263.

15. Ursing J, Kofoed PE, Rodrigues A, Rombo L, Gil JP: Plasmodium falciparum genotypes associated with chloroquine and amodiaquine resistance in Guinea-Bissau. Am J Trop Med Hyg 2007, 76:844-848.

16. Picot $S$, Olliaro P, de Monbrison F, Bienvenu AL, Price RN, Ringwald P: A systematic review and meta-analysis of evidence for correlation between molecular markers of parasite resistance and treatment outcome in falciparum malaria. Malar J 2009, 8:89.

17. Babiker HA, Pringle SJ, Abdel-Muhsin A, Mackinnon M, Hunt $P$, Walliker D: High-level chloroquine resistance in Sudanese isolates of Plasmodium falciparum is associated with mutations in the chloroquine resistance transporter gene pfcrt and the multidrug resistance Gene pfmdr1. $J$ Infect Dis 2001, 183:1535-1538.

18. Basco LK, Ringwald P: Molecular epidemiology of malaria in Yaounde, Cameroon. VI. Sequence variations in the Plasmodium falciparum dihydrofolate reductase-thymidylate synthase gene and in vitro resistance to pyrimethamine and cycloguanil. Am J Trop Med Hyg 2000, 62:271-276.

19. Hyde JE: Drug-resistant malaria - an insight. FEBS J 2007, 274:4688-4698.

20. Kublin JG, Dzinjalamala FK, Kamwendo DD, Malkin EM, Cortese JF, Martino LM, Mukadam RA, Rogerson SJ, Lescano AG, Molyneux ME, Winstanley PA, Chimpeni P, Taylor TE, Plowe CV: Molecular markers for failure of sulfadoxine-pyrimethamine and chlorproguanil-dapsone treatment of Plasmodium falciparum malaria. J Infect Dis 2002, 185:380-388.

21. Lynch C, Pearce R, Pota H, Cox J, Abeku TA, Rwakimari J, Naidoo I, Tibenderana J, Roper C: Emergence of a dhfr mutation conferring high level drug resistance in Plasmodium falciparum populations from southwest Uganda. J Infect Dis 2008, 197:1598-1604.

22. Eckstein-Ludwig U, Webb RJ, Van Goethem ID, East JM, Lee AG, Kimura M, O'Neill PM, Bray PG, Ward SA, Krishna S: Artemisinins target the SERCA of Plasmodium falciparum. Nature 2003, 424:957-961.

23. Uhlemann AC, Cameron A, Eckstein-Ludwig U, Fischbarg J, Iserovich $P$, Zuniga FA, East M, Lee A, Brady L, Haynes RK, Krishna S: A single amino 
acid residue can determine the sensitivity of SERCAs to artemisinins. Nat Struct Mol Biol 2005, 12:628-9.

24. Jambou R, Legrand E, Niang M, Khim N, Lim P, Volney B, Ekala MT, Bouchier C, Esterre P, Fandeur T, Mercereau-Puijalon OS: Resistance of Plasmodium falciparum field isolates to in-vitro artemether and point mutations of the SERCA-type PfATPase6. Lancet 2005, 366:1960-1963.

25. Yang Z, Zhang Z, Sun X, Wan W, Cui L: Molecular analysis of chloroquine resistance in Plasmodium falciparum in Yunnan Province China. Trop Med Int Health 2007, 12:1051-60.

26. Zhang GQ, Guan YY, Zheng B, Wu S, Tang LH: Molecular assessment of Plasmodium falciparum resistance to antimalarial drugs in China. Trop Med Int Health 2009, 14:1266-71.

27. WHO: Methods and techniques for clinical trials on antimalarial drug efficacy: genotyping to identify parasite populations. Geneva: World Health Organization; 2008. http://www.who.int/malaria/resistance.

28. Fidock DA, Nomura T, Talley AK, Cooper RA, Dzekunov SM, Ferdig MT, Ursos LM, Sidhu AB, Naudé B, Deitsch KW, Su XZ, Wootton JC, Roepe PD, Wellems TE: Mutations in the $P$. falciparum digestive vacuole transmembrane protein PfCRT and evidence for their role in chloroquine resistance. Mol Cell 2000, 6:861-871.

29. Lakshmanan V, Bray PG, Verdier-Pinard D, Johnson DJ, Horrocks $P$, Muhle RA, Alakpa GE, Hughes RH, Ward SA, Krogstad DJ, Sidhu AB, Fidock DA: A critical role for PfCRT K76T in Plasmodium falciparum verapamil-reversible chloroquine resistance. EMBO J 2005, 24:2294-2305.

30. Wang RZ: Efficiency of pyrimethamine salt for $P$. vivax prophylaxis. Railway Medicine 1981, 4:246-247.

31. Yang HL, Yang PF, Dong Y, Che LG, Chen WC, He H, Liu DQ, Liu RJ, Zhan B, Zhang CY, Gao DQ: Longitudinal surveillance of chloroquine resistance of Plasmodium falciparum after cessation of medication in south Yunnan. Zhongguo Ji Sheng Chong Xue Yu Ji Sheng Chong Bing Za Zhi 1994, 12:31-33.

32. Durrand V, Berry A, Sem R, Glaziou P, Beaudou J, Fandeur T: Variations in the sequence and expression of the Plasmodium falciparum chloroquine resistance transporter (Pfcrt) and their relationship to chloroquine resistance in vitro. Mol Biochem Parasitol 2004, 136:273-85.

33. Congpuong K, Na Bangchang K, Mungthin M, Bualombai $P$, Wernsdorfer WH: Molecular epidemiology of drug resistance markers of Plasmodium falciparum malaria in Thailand. Trop Med Int Health 2005, 10:717-722.

34. Guan YY, Tang LH, Hu L, Feng XP, Liu DQ: The point mutations in Pfcrt and Pfmdr1 genes in Plasmodium falciparum isolated from Hainan Province. Chin J Parasitol Parasit Dis 2005, 23:135-139.

35. Duraisingh $M T$, Jones $P$, Sambou I, von Seidlein $L$, Pinder $M$, Warhurst DC: The tyrosine- 86 allele of the pfmdr1 gene of Plasmodium falciparum is associated with increased sensitivity to the anti-malarials mefloquine and artemisinin. Mol Biochem Parasitol 2000, 108:13-23.

36. Foote SJ, Kyle DE, Martin RK, Oduola AM, Forsyth K, Kemp DJ, Cowman AF: Several alleles of the multidrug-resistance gene are closely linked to chloroquine resistance in Plasmodium falciparum. Nature 1990, 345:255-25.

37. Patel JJ, Thacker D, Tan JC, Pleeter P, Checkley L, Gonzales JM, Deng B, Roepe PD, Cooper RA, Ferdig MT: Chloroquine susceptibility and reversibility in a Plasmodium falciparum genetic cross. Mol Microbio/ 2010, 78:770-787

38. Sá JM, Twu O, Hayton K, Reyes S, Fay MP, Ringwald P, Wellems TE: Geographic patterns of Plasmodium falciparum drug resistance distinguished by differential responses to amodiaquine and chloroquine. Proc Natl Acad Sci USA 2009, 106:18883-18889.

39. Price RN, Uhlemann AC, Brockman A, MCGready R, Ashley E, Phaipun L, Patel R, Laing K, Looareesuwan S, White NJ, Nosten F, Krishna S: Mefloquine resistance in Plasmodium falciparum and increased pfmdr1 gene copy number. Lancet 2004, 364:438-447.

40. Veiga MI, Ferreira PE, Jörnhagen L, Malmberg M, Kone A, Schmidt BA, Petzold M, Björkman A, Nosten F, Gil JP: Novel polymorphisms in Plasmodium falciparum $\mathrm{ABC}$ transporter genes are associated with major ACT antimalarial drug resistance. PLoS One 2011, 6:20212.

41. Khim N, Bouchier C, Ekala MT, Incardona S, Lim P, Legrand E, Jambou R, Doung S, Puijalon OM, Fandeur T: Countrywide survey shows very high prevalence of Plasmodium falciparum multilocus resistance genotypes in Cambodia. Antimicrob Agents Chemother 2005, 49:3147-3152.

42. Anderson TJ, Nair S, Sudimack D, Williams JT, Mayxay M, Newton PN, Guthmann JP, Smithuis FM, Tran TH, van den Broek IV, White NJ, Nosten F:
Geographical distribution of selected and putatively neutral SNPs in Southeast Asian malaria parasites. Mol Biol Evol 2005, 22:2362-2374.

43. Noedl H: Artemisinin resistance: how can we find it? Trends Parasitol 2005, 21:404-405.

44. Dondorp AM, Nosten F, Yi P, Das D, Phyo AP, Tarning J, Lwin KM, Ariey F, Hanpithakpong W, Lee SJ, Ringwald P, Silamut K, Imwong M, Chotivanich K, Lim P, Herdman T, An SS, Yeung S, Singhasivanon P, Day NP, Lindegardh N, Socheat $D$, White $\mathrm{NJ}$ : Artemisinin resistance in Plasmodium falciparum malaria. N Engl J Med 2009, 361:455-467.

45. Noedl H, Se Y, Schaecher K, Smith BL, Socheat D, Fukuda MM: Evidence of artemisinin-resistant malaria in western Cambodia. N Engl J Med 2008, 359:2619-2620.

46. Noedl H, Se Y, Sriwichai S, Schaecher K, Teja-lsavadharm P, Smith B, Rutvisuttinunt W, Bethell D, Surasri S, Fukuda MM, Socheat D, Chan Thap L: Artemisinin resistance in Cambodia: a clinical trial designed to address an emerging problem in Southeast Asia. Clin Infect Dis 2010, 51:82-89.

47. Dahlström S, Veiga MI, Ferreira $P$, Mårtensson A, Kaneko A, Andersson B, Björkman A, Gil JP: Diversity of the sarco/endoplasmic reticulum $\mathrm{Ca}(2+)$-ATPase orthologue of Plasmodium falciparum (PfATP6). Infect Genet Evol 2008, 8:340-345.

48. Bertaux L, le Quang H, Sinou V, Thanh NX, Parzy D: New PfATP6 mutations found in Plasmodium falciparum isolates from Vietnam. Antimicrob Agents Chemother 2009, 53:4570-4571.

49. Dahlström S, Veiga MI, Ferreira P, Mårtensson A, Kaneko A, Andersson B, Björkman A, Gil JP: Diversity of the sarco/endoplasmic reticulum Ca2 + -ATPase orthologue of Plasmodium falciparum (PfATP6). Infect Genet Evol 2008, 8:340-345.

50. Ibrahim ML, Khim N, Adam HH, Ariey F, Duchemin JB: Polymorphism of PfATPase in Niger: detection of three new point mutations. Malar J 2009, 8:28.

51. Menegon M, Sannella AR, Majori G, Severini C: Detection of novel point mutations in the Plasmodium falciparum ATPase6 candidate gene for resistance to artemisinins. Parasitol Int 2008, 57:233-235.

52. Imwong M, Dondorp AM, Nosten F, Yi P, Mungthin M, Hanchana S, Das D, Phyo AP, Lwin KM, Pukrittayakamee S, Lee SJ, Saisung S, Koecharoen K, Nguon C, Day NP, Socheat D, White NJ: Exploring the contribution of candidate genes to artemisinin resistance in Plasmodium falciparum. Antimicrob Agents Chemother 2010, 54:2886-2892.

doi:10.1186/1475-2875-11-243

Cite this article as: Huang et al:: Molecular epidemiology of drug resistance markers of Plasmodium falciparum in Yunnan Province, China. Malaria Journal 2012 11:243.

\section{Submit your next manuscript to BioMed Central and take full advantage of:}

- Convenient online submission

- Thorough peer review

- No space constraints or color figure charges

- Immediate publication on acceptance

- Inclusion in PubMed, CAS, Scopus and Google Scholar

- Research which is freely available for redistribution 